\title{
Internal capabilities and SMEs performance: A case of textile industry in Pakistan
}

\author{
Muhammad Zulqarnain Arshad ${ }^{\mathrm{a}^{*}}$ and Darwina Arshad
}

${ }^{a}$ School of Business Management, Universiti Utara Malaysia, Malaysia

\begin{tabular}{l}
\hline C H R O N I C L E \\
\hline Article history: \\
Received: October 18, 2018 \\
Received in revised format: No- \\
vember 11, 2018 \\
Accepted: January 3, 2019 \\
Available online: \\
January 3, 2019 \\
\hline Keywords: \\
Innovation Capability \\
Absorptive Capacity \\
SMEs Performance \\
\hline
\end{tabular}

\author{
A B S T R A C T
}

\begin{abstract}
The small and medium-sized enterprises (SMEs) play an important role on the growth of the economies of developing countries. In Pakistan, SMEs hold about 90 percent of the total businesses including the textile industry. The performance of SMEs in the textile industry is influenced by several factors including the internal capabilities of the firms. Hence the primary objective of the study is to examine the relationship between the internal capabilities namely Innovation Capability, Absorptive Capacity and SMEs Performance among textile firms in Pakistan. The study is conducted using quantitative research. There are 377 questionnaires distributed among textiles SMEs of Pakistan and they were analyzed using some statistical tests. The results reveal that innovation capability and absorptive capacity influenced the performance of SMEs, positively.
\end{abstract}

(c) 2019 by the authors; licensee Growing Science, Canada

\section{Introduction}

SMEs play an important role on the growth of the economies of the developing countries. SMEs are also known as major sources of the employment generation for various countries (Dundon \& Wilkinson, 2018). However, Chiang (2018) stated that, few studies have been conducted associated with the SMEs performance in developing countries including Pakistan. Previous scholars underlined the importance of SMEs, but there is not much on relationship between factors influencing SMEs and performance (Shah et al., 2016). There are several factors related to capabilities influencing SMEs performance such as innovation capabilities (Dooley et al., 2017) and absorptive capacity (Limaj \& Bernroider, 2017). Innovation capability is the main resource for the success of the firms; however still less attention is devoted to this variable in studies related to the developing countries. In Pakistan, there are few studies identifying the impact of innovation capabilities on SMEs performance (Haroon et al., 2013). Whereas, absorptive capacity refers to the capability of SMEs capability to assimilate, value, and apply knowledge gain from external environment and leverage the knowledge in a productive manner (Limaj $\&$ Bernroider, 2017). However, most studies on absorptive capacity related with the large organizations, and less studies were conducted in the SMEs context (Becheikh, 2013; Guo \& Wang, 2014; Tzokas et al., 2015, Rodríguez-Serrano \& Martín-Armario, 2017). Hence, the objective of this research paper is to identify the effect of innovation capability and absorptive capacity on SMEs performance in the context of Pakistan.

* Corresponding author.

E-mail address: muhammad.zulqarnain11@gmail.com (M. Z. Arshad)

(C) 2019 by the authors; licensee Growing Science, Canada doi: $10.5267 /$ j.msl.2019.1.001 


\section{Literature review}

\subsection{Theory}

This study is underpinned by Resource Based View (RBV) Theory. This theory posited that the unique resources of a firm generate competitive advantages that lead to the performance and sustainability of the firms in the industry (Wernerfelt, 1984; Barney, 1991; Peteraf, 1993). Moreover, RBV emphasized on firms' competitive resources, especially on a firm's unique resources as it is crucial for growth. RBV consists of tangible and intangible capabilities. For this study, we focused on the intangible capabilities namely innovation capabilities and absorptive capacity. Innovation capabilities' concept in RBV posits that firms optimally exploit their resources in order to gain their competitive advantages through the firm's ability to innovate in their operations (Slater et al., 2014; Nada \& Ali, 2015). Also, for the second capability to be included in this study, absorptive capacity, is considered as strategic capability because it is a path-dependent, firm-specific, and a socially embedded way of using other firm's knowledge to create competitive advantage from the external factors (Nagati \& Rebolledo, 2012).

\subsection{SMEs Performance}

Organizational success is generally denoted by the term firm performance. It is explains the achievement of firms outcomes based on the strategic planning formulated to achieve their objectives. Furthermore, performance has been defined as "The comparison of the value created by a firm with the value owners expected to receive from the firm" (Alchian \& Damsetz, 1972). Also, performance can be seen as the construct viewed it as "The way organization carries its objectives into effect" (Flapper et al., 1996). Furthermore, firm performance also can be measured using the comparison between the actual outputs against its input. Hence, performance measurement enables organizations to emphasis on units that need enhancement by assessing the work progress level in terms of cost, time and quality along with associating in capacities by greater output (Pešalj et al., 2018). Therefore the firm performance is firm's ability to achieve and accomplish its objectives by using all the firm's resources in an efficient and effective manner. SMEs hold $99 \%$ of the total establishments of the business in Pakistan. They are contributing $40 \%$ to total GDP of the country, $25 \%$ of total exports, $80 \%$ employment of non-agriculture labor force and 35\% of value added manufacturing (Khalique et al., 2011; Hafeez et al., 2013). Pakistan is Agro Based economy and the second largest sector for growth domestic product (GDP) contribution. Textile industry comes in the top of the manufacturing sector. It contributes $21 \%$ in manufacturing sector of Pakistan. There are total of 27250 SMEs textile units in Pakistan. (Ministry of Textile Industry Pakistan, 2016; SMEDA, 2016). Due to these issues, more studies related to the SMEs performance must be conducted in the textile industry in Pakistan.

\subsection{Innovation Capability and Performance}

Innovation capability is vital because it enables the firms to leverage their advantages to achieve firm performance. Saunila et al. (2013) stated that innovation capabilities vary from firm to firm and it also varies by type of innovation and various effective factors. As postulated by Perdomo-Ortiz et al. (2006), from the RBV perspective, "in order for firm to innovate, a firm requires the capability for innovation". Previous scholars acknowledged that innovation capability help the firms gain higher performance and sustainable competitive advantage (Saunila et al., 2012). Dooley et al. (2017) stressed that the firms with better innovation capability yield double sales profits compared with the firms with less or no

innovation capability. For that reason, Hurley and Hult (1998) stated that innovation capability is fundamental element for the constant growth and its sustainability. Hence the hypothesis is stated as follows:

$\mathrm{H}_{1}$ : Innovation capability significantly influences SMEs performance 
The concept of absorptive capacity was introduced in the 1980s, through the acquisition and application of new knowledge as the essential ingredient to achieve firm's competitiveness. The contribution made by Cohen and Levinthal (1990, p.128) is largely acknowledged as the founding paper. They defined absorptive capacity as "the ability of a firm to recognize the value of new external information, assimilate it, and apply it to commercial ends". Zahra and George (2002) provided an overall model that considers absorptive capabilities as a dynamic construct. Hughes et al. (2017) acknowledged that absorptive capacity in a knowledge based economy is considered as a crucial dynamic resource or capability. Furthermore, Limaj and Bernroider (2019) further explained that absorptive capacity is a key driver for firm's competitiveness. In previous researches, the absorptive capacity was examined in many performance models, and most of them acknowledged or proved significance positive influence with the performance of the firm (Nagati \& Rebolledo, 2012; Ali et al., 2016; Herath \& Mahmood, 2014; Tzokas et al., 2015;). Based on the above discussion, we can hypothesis that

$\mathrm{H}_{2}$ : Absorptive capacity significantly influences SMEs performance

\section{Theoretical framework}

On the basis of literature discussed above, the theoretical framework is mentioned below.

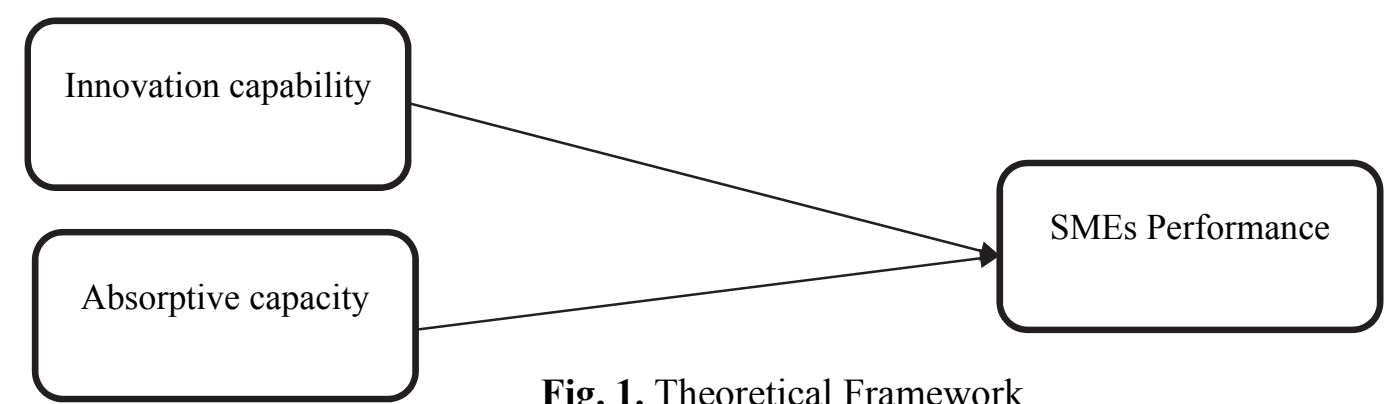

\section{Methodology}

In this research survey, questionnaire was used to collect the data among textile SMEs of Pakistan. The population of respondents included owners, CEO or managing director and senior manager. Simple random sampling technique was used in this research. The list of SMEs was obtained from SMEDA (Small and Medium Enterprises Development Authority) (SMEDA, 2016). According to the registered list in the Small Medium Development Authority (SMEDA), there were 27,250 small and mediumscale textile firms (Pakistan Bureau of Statistics, 2015). Based on Krejcie and Morgan (1970), there were 379 sample required to represent the population. Therefore 379 questionnaires were distributed in Textile SMEs out of which 350 were returned and usable. There are three variables involved in this research study namely; firm performance, innovation capability and absorptive capacity. Firm performance measure was adopted from Wiklund and Shepherd (2003) which consists of 10 items. The innovation capability was measured by 20 items: product innovativeness ( 4 items), market innovativeness (4 items), process innovativeness (4 items), behavioral innovativeness (4 items) and strategic innovativeness (4 items) was adopted from Wang and Ahmed (2004). The absorptive capacity scale was adopted by Flatten et al. (2011), which was measured by 16 items: acquisition (4 items), assimilation (4 items), transformation (4 items), and exploitation (4 items). Answers were elicited on a 7-point Likert scale ranging from $7=$ 'strongest agree' to $1=$ 'strongly disagree'. Before proceeding the collection of complete data, a pilot study was conducted. The questionnaire was distributed among 50 respondents but got the valid responses from 35 respondents. The reliability coefficient of Cronbach's alpha was used to assess the consistency of the scale. All the variables met the threshold valve of Cronbach's alpha (i.e. 0.7). The Cronbach's alpha value of firm performance, innovation capability and absorptive capacity were $0.91,0.879$ and 0.90 . The study used structural equation modelling (SEM) and applied 
partial least squares (PLS) using Smart PLS 3.2.7 to assess the Measurement model and structural model. The first step in this study focuses on construct reliability and validity (Measurement Model), whereas the second step tests structural relationships among the latent constructs (Structural Model). There were $350(92 \%)$ respondents, out of 379 respondents who finally made it to analysis, who were CEOs/managing directors in their respected organizations while $32(9 \%)$ of them were senior managers. $315(90 \%)$ of the respondents were male and $35(10 \%)$ of them were female. In addition, married among the respondents constituted $82 \%$, representing 287 respondents, of the entire sampled respondents while singles constituted 18\% (63 respondents). Majority of the respondents (53\%) were between 31-40 years of age. This is followed by the fact that 101 of them (29\%) were within the 41-50 age bracket. While 42 of the respondents $(12 \%)$ fall between $20-30$ years of age bracket, only $21(6 \%)$ were above 50 years of age.

\section{Results}

Primarily data analysis has been conducted to meet the assumption of running the PLS-SEM. After that measurement model and structural model have been assessed by PLS-SEM.

\subsection{Measurement model Assessment}

Measurement model has been used to assess the reliability and validity of the constructs (Hair et al., 2010). The model is Reflective-Reflective and the constructs are higher-order. Repetitive indicator approach has been used to assess the model (Becker et al., 2012). For indicator reliability, Cronbach Alpha and composite reliability (CR) were evaluated and for Validity, convergent validity (AVE) and discriminant validity were examined. The results from this study revealed that composite-reliability (CR) values are 0.941 (innovation capability), 0.895 (absorptive capacity) and 0.926 (Firm Performance) as shown in Table 1. The Cronbach Alpha values are 0.933 (innovation capability), 0.934 (absorptive capacity) and 0.945 (Firm Performance) as shown in Table 1 and Fig. 1.

Table 1

Reliability and Validity of the constructs

\begin{tabular}{|c|c|c|c|c|}
\hline & Cronbach's Alpha & rho $\mathrm{A}$ & $\mathrm{CR}$ & AVE \\
\hline FIRM PERFORMANCE & 0.945 & 0.859 & 0.926 & 0.635 \\
\hline INNOCAPABILITY & 0.933 & 0.934 & 0.941 & 0.616 \\
\hline INPD & 0.881 & 0.884 & 0.912 & 0.628 \\
\hline INPR & 0.863 & 0.866 & 0.902 & 0.653 \\
\hline INMK & 0.852 & 0.855 & 0.911 & 0.694 \\
\hline INSTG & 0.923 & 0.934 & 0.935 & 0.692 \\
\hline INBH & 0.936 & 0.937 & 0.944 & 0.547 \\
\hline ABSORPTIVE CAPACITY & 0.934 & 0.845 & 0.895 & 0.681 \\
\hline ABAC & 0.847 & 0.872 & 0.904 & 0.654 \\
\hline ABAS & 0.856 & 0.835 & 0.865 & 0.688 \\
\hline ABTR & 0.778 & 0.877 & 0.914 & 0.634 \\
\hline ABEX & 0.835 & 0.862 & 0.894 & 0.678 \\
\hline
\end{tabular}

Convergent-validity assessed by AVE which values are 0.616 (Innovation Capability), 0.681 (Absorptive Capacity) and 0.635 (Firm Performance) as shown in Table 1. Discriminant validity for this model has been measured by Fornell-Larcker Criterion (Hair et al., 2010) as shown in Table 2. It indicates that the square root of AVE (diagonal) is higher than the correlations (off-diagonal) for all reflective constructs. 


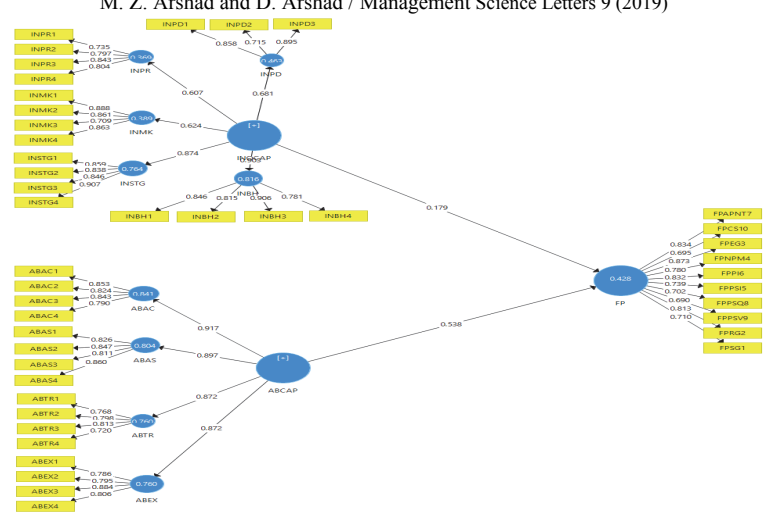

Note: INPD = Innovation Capability (Product Innovation); INPR = Innovation Capability (Process Innovation); INMK $=$ Innovation Capability (Market Innovation); INSTG = Innovation Capability (Strategic Innovation); INBH = Innovation Capability (Behavioral Innovation); $\mathrm{ABAC}=$ Absorptive Capacity (Acquisition), ABAS $=$ Absorptive Capacity (Assimilation), ABTR = Absorptive Capacity (Transformation), $\mathrm{ABEX}=$ Absorptive Capacity (Exploitation) and $\mathrm{FP}=\mathrm{SME}$ performance.

Table 2

Fig. 1. PLS Algorithm

Fornell-Larcker Criterion

\begin{tabular}{|c|c|c|c|c|c|c|c|c|c|c|}
\hline & $\mathrm{BAC}$ & ABAS & ABEX & ABTR & FP & INBH & INMK & INPD & INPR & INSTG \\
\hline $\mathrm{ABAC}$ & 0.828 & & & & & & & & & \\
\hline ABAS & 0.772 & 0.836 & & & & & & & & \\
\hline ABEX & 0.722 & 0.718 & 0.819 & & & & & & & \\
\hline ABTR & 0.816 & 0.663 & 0.657 & 0.875 & & & & & & \\
\hline FP & 0.531 & 0.572 & 0.544 & 0.621 & 0.737 & & & & & \\
\hline INBH & 0.453 & 0.521 & 0.519 & 0.495 & 0.458 & 0.838 & & & & \\
\hline INMK & 0.373 & 0.217 & 0.332 & 0.355 & 0.179 & 0.594 & 0.833 & & & \\
\hline INPD & 0.327 & 0.347 & 0.322 & 0.352 & 0.272 & 0.598 & 0.738 & 0.826 & & \\
\hline INPR & 0.384 & 0.219 & 0.353 & 0.434 & 0.253 & 0.569 & 0.694 & 0.691 & 0.795 & \\
\hline INSTG & 0.328 & 0.463 & 0.376 & 0.434 & 0.343 & 0.679 & 0.606 & 0.658 & 0.573 & 0.863 \\
\hline
\end{tabular}

Note: INPD = Innovation Capability (Product Innovation); INPR = Innovation Capability (Process Innovation); INMK = Innovation Capability (Market Innovation); INSTG = Innovation Capability (Strategic Innovation); INBH = Innovation Capability (Behavioral Innovation); $\mathrm{ABAC}=$ Absorptive Capacity (Acquisition), ABAS $=$ Absorptive Capacity (Assimilation), ABTR = Absorptive Capacity (Transformation), $\mathrm{ABEX}=$ Absorptive Capacity (Exploitation) and $\mathrm{FP}=\mathrm{SME}$ performance.

\subsection{Structural model Assessment}

Once the reliability and validity have been achieved in measurement model, we have assessed the structural model. In structural model we have examined the path coefficient (Hypothesis testing), Coefficient of determination $\left(\mathrm{R}^{2}\right.$ value $)$ and effect size $\left(f^{2}\right)$. The coefficient of determination $\left(\mathrm{R}^{2}\right.$ value $)$ of this study is $42.8 \%$, which means that INOCAP and ABCAP explained $42.8 \%$ variance of endogenous variable i.e. firm performance as shown in above Fig. 1. For evaluating the path coefficient (hypotheses testing), we run the bootstrapping in Smart-PLS. two-tailed test with $1 \%$ level of significance to assess the P-Valve and T-statistics to test the significance or insignificance of hypothesis. Table 3 and Fig. 2 show that Innovation capability had a significant effect on endogenous variable (firm performance) ( $\beta=0.179, \mathrm{t}=2.590, \mathrm{p}<0.01)$, therefore $\mathrm{H}_{1}$ is supported and Absorptive capacity has a significant effect on endogenous variable (firm performance) $(\beta=0.538, \mathrm{t}=7.877, \mathrm{p}<0.01)$, therefore $\mathrm{H}_{2}$ is also supported.

Table 3

Results of the Structural Model Path Coefficient Direct Hypothesis Testing

\begin{tabular}{cccccccc}
\hline Hypotheses & Relationships & Beta & Mean & Std Deviation & T-Values & P-Values & Decision \\
\hline H1 & INOCAP $\rightarrow$ FP & 0.179 & 0.181 & 0.071 & 2.590 & $0.001^{*}$ & Supported \\
H2 & ABCAP $\rightarrow$ FP & 0.538 & 0.536 & 0.068 & 7.887 & $0.000^{*}$ & Supported \\
\hline
\end{tabular}

Once the hypotheses tested, we further investigated the effect size for the exogenous variables. In the Table 4, the endogenous variable (SME performance) was explained by innovation capability and absorptive capacity with effect size $\left(\mathrm{f}^{2}\right)$ of 0.175 and 0.347 respectively, indicating medium and large effect size of the two respective exogenous variables. 


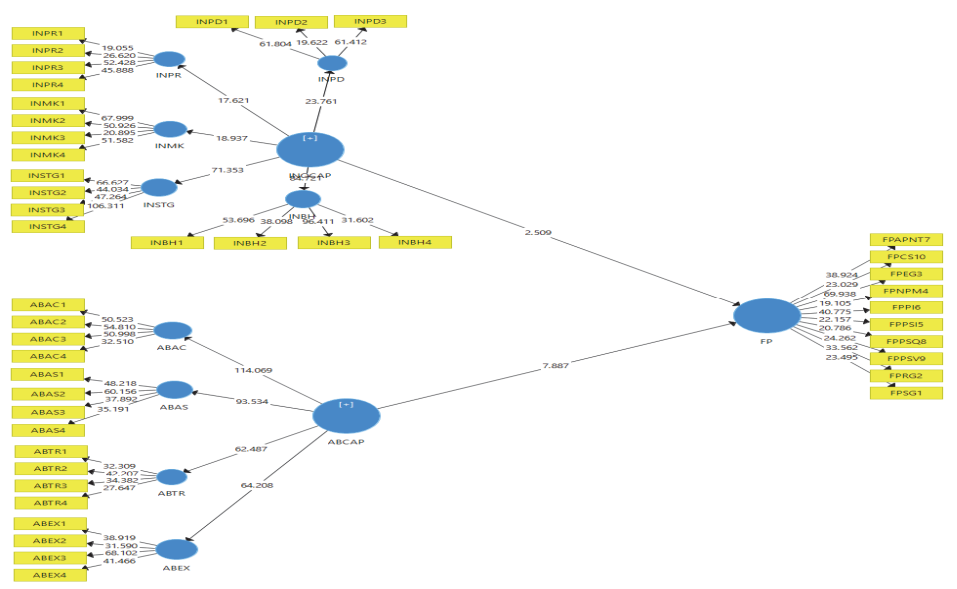

Note: level of significance $.001^{*}$

Note: INPD = Innovation Capability (Product Innovation); INPR = Innovation Capability (Process Innovation); INMK = Innovation Capability (Market Innovation); INSTG = Innovation Capability (Strategic Innovation); INBH = Innovation Capability (Behavioral Innovation); ABAC = Absorptive Capacity (Acquisition), ABAS = Absorptive Capacity (Assimilation), ABTR = Absorptive Capacity (Transformation), ABEX = Absorptive Capacity (Exploitation) and FP $=$ SME performance

Fig. 2. PLS Bootstrapping for Direct Hypothesis testing

Table 4

Effect size

\begin{tabular}{ccc}
\hline Exogenous Construct & F2 & Effect Size \\
\hline Innovation Capability & 0.175 & medium \\
Absorptive Capacity & 0.347 & large \\
\hline
\end{tabular}

Note: $0.02,0.15$, and 0.35 stand for small, medium and large

\section{Discussion}

This study underpinned by Resource Based View (RBV) Theory indicates that there are two types of resources i.e. tangible and intangible. Now a days the firms which more focus on intangible resources are more successful. Innovation capability and absorptive capacity are the intangible resources, therefore SMEs has to more focus on it for better performance. This study is one of the studies which address the importance of innovation capability and absorptive capacity in Textile SMEs of Pakistan.This study has empirically validated that the innovation capability had a significant effect on SMEs performance. Current study has revealed that innovation capability plays vital role in the enhancement of SMEs performance. The results of this study are consistent with the previous studies among innovation capability - firm performance (Saunila et al., 2014; Aryanto et al., 2015; Dooley et al., 2017).

This study also empirically validated that the absorptive capacity had a significant effect on SMEs performance. This study has explained that absorptive capacity also plays significant role in attaining the high level of SMEs performance. Textile SMEs is lacking behind because of external knowledge absorption in their internal process workers. Hence internal capabilities of firm (absorptive capacity) building are crucial for the sustainbale growth of textile sector SMEs. This study is also consistent with the previous studies among absorptive capacity - firm performance (Ali et al., 2016; Tzokas et al., 2015; Limaj \& Bernroider, 2017).

\section{Conclusion and recommendation}

Pakistan is Agro-based economy and textile is the biggest sector contributing in GDP but the Environmental is uncertain, therefore the sector is not progressing in the right way. SMEs must reconfigure their internal resources and capabilities to gain higher performance and gain competitive advantage 
over their competitors. This study has focused on the manufacturing textile SMEs of developing country i.e. Pakistan. The previous studies more focused on the developed economies, therefore this research empirically addressed the research gap and contributed in the literature. A review of prior literature has indicated that innovation capability and absorptive capacity had a significant effect on the SMEs performance. The findings of this study helps SMEDA (Small and Medium enterprises Development Authority) of Pakistan develop guidelines and policies related to the SMEs. The findings of this research helps the Academia and practitioners the importance of innovation capability and absorptive capacity. Mostly the research studies on these variables have been conducted in developed economies and among large firms, hence more studies are required among SMEs. Future scholars must focus on empirical testing on the effect of the internal capabilities, namely innovation capability and absorptive capacity impacting other sectors of SMEs performance in the emerging economy like Pakistan.

\section{References}

Ali, M., Seny Kan, K. A., \& Sarstedt, M. (2016). Direct and configurational paths of absorptive capacity and organizational innovation to successful organizational performance. Journal of Business Research, 69(11), 5317-5323.

Aryanto, R., Fontana, A., \& Afiff, A. Z. (2015). Strategic human resource management, innovation capability and performance: An empirical study in Indonesia software industry. Procedia-Social and Behavioral Sciences, 211, 874-879.

Becheikh, N. (2013). The impact of knowledge acquisition and absorptive capacity on technological innovations in developing countries: Evidence from Egyptian Small and Medium-Sized Enterprises. Journal of African Business, 14(3), 127-140.

Becker, J. M., Klein, K., \& Wetzels, M. (2012). Hierarchical latent variable models in PLS-SEM: guidelines for using reflective-formative type models. Long Range Planning, 45(5-6), 359-394.

Chiang, M. H. (2018). The Changing Role of SMEs in Taiwan's and South Korea's Economies. $\mathrm{n}$ PostIndustrial Development in East Asia (pp. 49-70). Palgrave Pivot, Singapore.

Cohen, W. M., \& Levinthal, D. A. (1990). Absorptive Capacity: a new Perspective on Learning and Innovation. Administrative Science Quarterly, 35(1), 128-152.

Dooley, L., Kenny, B., \& O’Sullivan, D. (2017). Innovation capability development: case studies of small enterprises in the LMT manufacturing sector. Small Enterprise Research, 24(3), 233-256.

Dundon, T., \& Wilkinson, A. (2018). HRM in small and mediumsized enterprises (SMEs). In Human resource management (pp. 194-211). Routledge.

Flatten, T. C., Engelen, A., Zahra, S. A., \& Brettel, M. (2011). A measure of absorptive capacity: Scale development and validation. European Management Journal, 29(2), 98-116.

Flapper, S. D. P., Fortuin, L., Stoop, P. P. M. M., Douwe P. Flapper, S., Fortuin, L., Stoop, P. P. M. M., ... Stoop, P. P. M. M. (1996). Towards consistent performance management systems. International Journal of Operations \& Production Management, 16(7), 27-37.

Guo, B., \& Wang, Y. Q. (2014). Environmental turbulence, absorptive capacity and external knowledge search among Chinese SMEs. Chinese Management Studies, 8(2), 258-272.

Nagati, H., \& Rebolledo, C. (2012). The role of relative absorptive capacity in improving suppliers' operational performance. International Journal of Operations \& Production Management, 32(5), 611-630.

Hafeez, M. H., Shariff, M. N. M., \& bin Mad Lazim, H. (2013). Does Innovation and Relational Learning Influence SME Performance? An Empirical Evidence from Pakistan. Asian Social Science, 9(15), 204.

Hair, J. F. (2010). Black, WC, Babin, BJ, \& Anderson, RE (2010). Multivariate data analysis, 7.

Herath, H. M. A., \& Mahmood, R. (2014). Strategic orientations and SME performance: Moderating effect of absorptive capacity of the firm. Asian Social Science, 10(13), 95-107.

Hughes, P., Hodgkinson, I. R., Hughes, M., \& Arshad, D. (2017). Explaining the entrepreneurial orientation-performance relationship in emerging economies: The intermediate roles of absorptive capacity and improvisation. Asia Pacific Journal of Management, 1-29.Kim, G., \& Huh, M. (2015). Innovation and survival in Korean SMEs: the moderating effect of competitive strategy. Asian 
Journal of Technology Innovation, 23(1), 107-119.

Hurley, R. F., \& Hult, G. T. M. (1998). Innovation, market orientation, and organizational learning: an integration and empirical examination. The Journal of Marketing, 62(3), 42-54.

Krejcie, R. V., \& Morgan, D. W. (1970). Determining sample size for research activities. Educational and Psychological Measurement, 30(3), 607-610.

Limaj, E., \& Bernroider, E. W. (2019). The roles of absorptive capacity and cultural balance for exploratory and exploitative innovation in SMEs. Journal of Business Research, 94, 137-153.

Nada, N., \& Ali, Z. (2015). Service value creation capability model to assess the service innovation capability in SMEs. In Procedia CIRP (Vol. 30, pp. 390-395).

Nagati, H., \& Rebolledo, C. (2012). The role of relative absorptive capacity in improving suppliers' operational performance. International Journal of Operations \& Production Management, 32(5), 611-630.

Pešalj, B., Pavlov, A., \& Micheli, P. (2018). The use of management control and performance measurement systems in SMEs: A levers of control perspective. International Journal of Operations \& Production Management, 38(11).

Perdomo-Ortiz, J., González-Benito, J., \& Galende, J. (2006). Total quality management as a forerunner of business innovation capability. Technovation, 26(10), 1170-1185.

Peteraf, M. A. (1993). The cornerstones of competitive advantage: A resource-based view. Strategic Management Journal, 14(3), 179-191.

Rodríguez-Serrano, M. Á., \& Martín-Armario, E. (2017). Born-Global SMEs, Performance, and Dynamic Absorptive Capacity: Evidence from Spanish Firms. Journal of Small Business Management.

Saunila, M., Pekkola, S., \& Ukko, J. (2014). The relationship between innovation capability and performance: The moderating effect of measurement. International Journal of Productivity and Performance Management, 63(2011), 234-249.

Shah, M. H., Othman, A. R. B., \& Mansor, M. N. bin. (2016). Moderating Role of Environmental Turbulence on the Relationship between Innovative Practice, Mentoring, Social Capital and Small Business Performance. Asian Journal of Multidisciplinary Studies, 4(8), 202-219.

Slater, S. F., Mohr, J. J., \& Sengupta, S. (2014). Radical product innovation capability: Literature review, synthesis, and illustrative research propositions. Journal of Product Innovation Management, 31(3), 552-566.

SMEDA. (2016). Compliance with international standards. Retrieved from http://www.smeda.org.pk

Tzokas, N., Kim, Y. A., Akbar, H., \& Al-Dajani, H. (2015). Absorptive capacity and performance: The role of customer relationship and technological capabilities in high-tech SMEs. Industrial Marketing Management, 47, 134-142.

Wang, C. L., \& Ahmed, P. K. (2004). The development and validation of the organizational innovativeness construct using confirmatory factor analysis. European Journal of Innovation Management, 7(4), 303-313.

Wernerfelt, B. (1984). A resource-based view of the firm. Strategic Management Journal, 5(2), 171180.

Wiklund, J., \& Shepherd, D. (2003). Knowledge-based resources, entrepreneurial orientation, and the performance of small and medium-sized businesses. Strategic Management Journal, 24(13), 13071314.

Zahra, S. A., \& George, G. (2002). Absorptive capacity: A review, reconceptualization, and extension. Academy of Management Review, 27(2), 185-203.

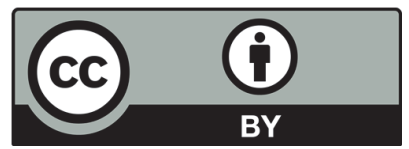

(C) 2019 by the authors; licensee Growing Science, Canada. This is an open access article distributed under the terms and conditions of the Creative Commons Attribution (CC-BY) license (http://creativecommons.org/licenses/by/4.0/). 